\title{
PEQUENAS AÇÕES SALVAM VIDAS
}

\author{
FELIPE GOMES DA SILVA, Luiz \\ DA SILVA ARAUJO, Tiago ${ }^{2}$ \\ FERNANDO BOFF ZARPELON, Luis ${ }^{33}$
}

\section{RESUMO}

O projeto Pequenas Ações Salvam Vidas, desenvolvido por alunos da UNILA, por meio da Liga Universitária de Trauma e Emergência (LUTE), sob a tutela do professor orientador, ocorre em pontos estratégicos da tríplice fronteira e oeste do Paraná. O projeto é voltado à população, com o intuito de mudar a realidade da morbimortalidade da região, por meio da promoção de medidas de prevenção de acidentes e de técnicas de primeiros socorros para a população. As atividades acontecem por meio de aulas teórico-práticas, com supervisão do professor orientador, sobre prevenção de acidentes e técnicas de primeiros socorros. Acontecem treinamentos e simulados fora da universidade, além da elaboração de materiais próprios, de forma digital ou impressa. Para isso, alunos organizam diferentes abordagens a serem definidas de acordo com o perfil do público-alvo. Durante o processo, pode-se avaliar a transmissão de informações gratuita voltadas aos primeiros socorros, à prevenção do trauma e que podem ser expandidas para outras áreas do conhecimento, melhorando a saúde pública. Outro aspecto é o canal de comunicação que vem se formando entre a Universidade e a população, inspirando indivíduos a serem fontes multiplicadoras. Conclui-se que o conhecimento permite que a população possa adotar ações de prevenção do Trauma e da Emergência e realize procedimentos de primeiros socorros da forma correta, reconhecendo rapidamente o problema, chamando o socorro especializado e prestando o suporte básico à vida. Também, o canal de comunicação entre a Universidade e a população causa impacto nos determinantes de saúde da Tríplice Fronteira.

Palavras-chave: Educação em Saúde, Suporte Básico de Vida, Reanimação Cardiopulmonar.

\section{INTRODUÇÃO}

No Brasil, as doenças cardiovasculares são as principais causas de morte. Segundo o Ministério da Saúde, ocorreram 962.931 mortes em indivíduos com mais de 30 anos no ano 2009. As causas externas apresentam como a terceira

\footnotetext{
1 Estudante do curso de Medicina, ILACVN - UNILA; bolsista. E-mail: Ifg.silva.2017@aluno.unila.edu.br 2 Estudante do curso de Medicina, ILACVN - UNILA; bolsista. E-mail: ts.araujo.2017@aluno.unila.edu.br 3 Docente do curso de Medicina, ILACVN - UNILA; orientador dos bolsistas. E-mail: luis.zarpelon@unila.edu.br
} 
causa de morte no Brasill. Neste grupo, incluem-se as lesões provocadas por eventos no transporte, homicídios, agressões, quedas, afogamentos, envenenamentos, suicídios, queimaduras, lesões por deslizamento ou enchente, e outras ocorrências provocadas por circunstâncias ambientais. Em relação a mortalidade infantil, acidentes domésticos como afogamentos, quedas, queimaduras e intoxicações ainda são a principal causa de morte de crianças de até 9 anos no Brasil.

Podemos observar que grande parte dessas causas de mortes apresentadas acima, podem ser evitadas com medidas de prevenção, seja com mudança de hábito de vida ou retirada de fatores de risco, podendo assim reduzir a taxa de mortalidade da população. É, então, fundamental a participação da população no reconhecimento e intervenções em situações de emergência. ${ }^{2}$

Dessa forma, o objetivo deste trabalho é oferecer subsídio para formação e treinamentos sobretudo da população leiga da Tríplice Fronteira mudando a realidade da morbimortalidade no município de Foz do Iguaçu e seu entorno por meio da promoção de medidas decisivas de prevenção de acidentes e de técnicas de primeiros socorros para a população.

Desde a formulação e início do projeto mais de duas mil pessoas, entre leigos e profissionais da saúde, foram alcançadas. Em determinados eventos, mais de quatrocentos indivíduos foram ensinados em um único dia. Tais números demonstram a importância e alcance do Pequenas Ações Salvam Vidas.

\section{METODOLOGIA}

O projeto "Pequenas Ações Salvam Vidas", que se iniciou em março de 2017, tem ganhado espaço relevante na educação de saúde na região da Tríplice Fronteira e se desenvolve a partir de aulas teórico-práticas, simulações, treinamento, produção de materiais e produção científica.

As aulas teórico-práticas têm como finalidade 0 aprofundamento acadêmico, acontecendo uma vez na semana e durando cerca de 2 horas. Tais aulas seguiram eixos-temáticos, são eles: Suporte Básico de Vida; Prevenção e reconhecimento de Infarto agudo do miocárdio; Prevenção e reconhecimento de Acidente Vascular Cerebral; Prevenção e conduta no afogamento; Obstrução de 
Vias Aéreas por Corpos Estranhos; Cinemática do Trauma e Atendimento ao Politraumatizado.

A simulação e treinamento em parada cardiopulmonar, afogamento, atendimento ao politraumazado e outros assuntos pertinentes ao trauma, acontecem desde março de 2017 semanalmente. Enfatiza-se nessa relação à necessidade da aproximação da Universidade com a comunidade ações de impacto contínuo. Nesse sentido, o projeto desenvolveu e desenvolve ações em locais relevantes como Itaipu Binacional, Parque Nacional do Iguaçu, Shopping JL Cataratas, Escolas da tríplice fronteira, Unidades de Saúde e Hospital Municipal.

A elaboração de materiais próprios, de forma digital ou impressa tem o intuito de ensinar e conscientizar a sociedade sobre medidas básicas das temáticas abordadas, empoderando a mesma a ser mais ativa quanto às questões de sua própria saúde. Um grupo de alunos, após estudo prévio, está organizando diferentes abordagens para cada local das futuras intervenções, de acordo com a prevalência na população, taxa de mortalidade, impacto social e econômico. A divulgação será feita em locais estratégicos de Foz do Iguaçu ou locais de grandes aglomerados humanos da Tríplice Fronteira. Por fim, tem sido elaborado formulários e projetos de pesquisa a fim de avaliar o impacto e a eficácia de tais ações.

\section{FUNDAMENTAÇÃO TEÓRICA}

As doenças cardiovasculares (DCV) representam a primeira causa de morte no Brasil. Apesar da tendência de redução dos riscos de mortalidade por DCV no País e no mundo, algumas projeções indicam o aumento de sua importância relativa em países de baixa e média renda. As principais causas de óbito são as doenças isquêmicas do coração, as doenças cerebrovasculares e as doenças hipertensivas. Ressalte-se que essas causas são em grande parte evitáveis, diante da probabilidade de diminuição da ocorrência dessas mortes, se houver assistência ou prevenção oportunas.

As causas externas se apresentam como a terceira causa de morte no Brasil. Quando consideramos todas as causas na faixa de 1 a 39 anos de idade, as causas externas representam $58 \%$ de todos os óbitos. ${ }^{3}$ Neste grupo, incluemse as lesões provocadas por eventos no transporte, homicídios, agressões, 
quedas, afogamentos, suicídios, queimaduras, e outras ocorrências provocadas por circunstâncias ambientais.

Podemos observar que grande parte das causas de mortes apresentadas podem ser evitadas com medidas de prevenção, seja a partir da mudança de hábito de vida ou da retirada de fatores de risco. Por outro lado, em situações de emergência, saber avaliar a vítima e realizar um atendimento precoce permite um aumento na sobrevida e uma redução na ocorrência de sequelas. É, então, fundamental a participação da população no reconhecimento e intervenções em situações de emergência. O ensino de primeiros socorros no Brasil ainda é pouco difundido em detrimento de sua grande relevância e da quantidade de agravos à saúde que acontecem no Brasil, sendo necessárias intervenções adequadas para o treinamento da população.

\section{RESULTADOS}

Ao longo das ações, foi notório que em vários ambientes, inclusive nos de saúde, leigos e profissionais não sabiam como proceder de maneira correta em situações de emergência como em casos de paradas cardiorrespiratórias.

Em quase dois anos de funcionamento, estima-se que mais de 2000 pessoas tenham sido atingidas pelas ações. Por serem realizadas em escolas, locais de trânsito público, unidades básicas de saúde e outros ambientes, é possível variar o público atingido, o que corrobora os princípios de disseminação do conhecimento propagado pelo projeto.

\section{CONSIDERAÇÕES FINAIS}

O projeto Pequenas Ações Salvam vidas rapidamente se tornou conhecido no ambiente acadêmico. Fora dele, a comunidade tem se mostrado aberta e interessada no aprendizado na área do trauma, perfil que possibilita um impacto positivo nos determinantes de saúde de Foz do Iguaçu. O conhecimento e aperfeiçoamento constante e propagador permite que a população possa adotar, de modo ativo, ações de prevenção do Trauma e da Emergência e realize procedimentos de primeiros socorros da forma correta, reconhecendo rapidamente o problema, chamando o socorro especializado e prestando o 
suporte básico à vida. Através dos resultados obtidos até o presente momento e da resposta da população, pode-se aferir o sucesso do projeto e sua importância para Foz do Iguaçu e região.

\section{PRINCIPAIS REFERÊNCIAS BIBLIOGRÁFICAS}

BARROS, M. D. A.; XIMENES, R.; LIMA, M. L. C. Mortalidade por causas externas em crianças e adolescentes: tendências de 1979 a 1995. Rev. Saúde Pública. 2001;35(2):142-9.

CANESIN M.F.; CARDOSO, L.T.Q.; SOARES A.E.; MORETTI, M.A, TIMERMAN, S., RAMIRES, J. A. F. Campanhas públicas de ressuscitação cardiopulmonar: uma necessidade real. Rev. Soc. Cardiol. Estado São Paulo. 2001;11(2):512-8.

SZPILMAN, D. Afogamento - Perfil epidemiológico no Brasil - Ano 2012.

Publicado on-line em www.sobrasa.org, Julho de 2012. Trabalho elaborado com base nos dados do Sistema de Informação em Mortalidade (SIM) tabulados no Tabwin - Ministério da Saúde - DATASUS - 2012. Disponível em <http://www2.datasus.gov.br/DATASUS/index.php> Acesso em julho de 2012 